\title{
Escola da Floresta | Breves notas ou um texto-colagem escrito por muitas mãos e meios
}

\author{
Escola da Floresta | Brief Notes or a Text-Collage \\ Written by Many Hands and Midias
}

\author{
Escola da Floresta | Breves notas o un texto-collage \\ escrito por muchas manos y medios
}

Fábio Tremonte *

http://dx.doi.org/10.22409/poiesis. 2033.75-84

\begin{abstract}
RESUMO: A Escola da Floresta é uma experiência em pedagogias experimentais e radicais a partir de uma escola, inicialmente, nômade. Seu programa é baseado em descobrir, conhecer, ensinar e aprender a partir de outros possíveis saberes, sejam aqueles que utilizamos em nosso cotidiano, até saberes populares e ancestrais, passando pelos saberes ditos não-oficiais e presentes nos currículos oficiais. Como maneira de compartilhar esses conhecimentos, a escola propõe encontros de naturezas diversas.
\end{abstract}

PALAVRAS-CHAVE: escola; pedagogia experimental; pedagogia radical; outros saberes; encontros

\footnotetext{
* Fábio Tremonte é mestre em Artes Visuais pela Escola de Comunicações e Artes da Universidade de São Paulo. Bacharel em Artes com qualificação em multimídia e intermídia na Escola de Comunicações e Artes da Universidade de São Paulo. E-mail: fabio@fabiotremonte.com.
} 
ABSTRACT: The Escola da Floresta is an experience in experimental and radical pedagogies from an initially nomadic school. Its program is based on discovering, knowing, teaching and learning from other possible knowledges, be those that we use in our daily life, to popular and ancestral knowledge, passing through the knowledges no officials and present in the official curricula. As a way to share this knowledge, the school proposes meetings of different natures.

KEYWORDS: school; experimental pedagogy; radical pedagogy; other knowledge; meetings

RESUMEN: La Escola da Floresta es una experiencia en pedagogías experimentales y radicales a partir de una escuela, inicialmente, nómada. Su programa está basado en descubrir, conocer, enseñar y aprender de otros posibles saberes, sea aquellos que utilizamos en nuestro cotidiano, hasta saberes populares y ancestros, pasando por los saberes no oficiales y tapien aquellos presentes en los currículos oficiales. Como manera de compartir esos conocimientos, la escuela propone encuentros de diversas naturalezas.

PALABRAS CLAVE: escuela; pedagogía experimental; pedagogía radical; otros saberes; encuentros

Como citar: TREMONTE, Fábio. Escola da Floresta | Breves notas ou um textocolagem escrito por muitas mãos e meios. Poiésis, Niterói, v. 20, n. 33, p. 75-84, jan. /jun. 2019.

doi: http://dx.doi.org/10.22409/poiesis.2033.75-84

Poiésis, Niterói, v. 20, n. 33, jan./jun. 2019. 


\section{Escola da Floresta | Breves notas ou um texto-colagem escrito por muitas mãos e meios}

Iniciada em 2016, a Escola da Floresta existe [1] como um espaço nômade e temporário, acontecendo em lugares e momentos diversos e constituída a partir da intenção de criar possibilidades de encontro.

$* * *$ 
Se serve muito do que há ao seu redor. Da sua casa, da sua cidade, do seu ateliê, dos seus amigos, dos seus conhecidos e desconhecidos, dos espaços de arte, dos espaços públicos, dos públicos. Se serve também do que está acontecendo no domínio das políticas públicas, do que foi esquecido pelo sistema que rege essas políticas, joga com a profundidade de campo - se interessa "pelas formas de vida comunais que vêm, insistente e corajosamente, resistindo e recriando modos de viver ao longo dos séculos". E "se servir" diz respeito a uma relação de interdependência e de cooperação. [2]

$* * *$

As possíveis formas de encontro são aplicados tanto na dinâmica das proposições quanto na configuração e temas abordados e são elaborados a partir de um processo de pesquisa do contexto e conjuntura política e histórica da América latina, em processos de aprendizagem horizontal, desierarquizado, um lugar para ações e proposições coletivas na busca por imaginar novas e diferentes formas de vida que façam frente a um modelo de mundo desenvolvimentista e capitalista, em uma busca pela tentativa de experimentar um outro tempo, não-pautado pelo relógio nem pela produção, mas uma vivência de um tempo alargado, de estar junto.

$* * *$

\section{Anarcotropicalismo}

A Escola da Floresta baseia-se, inicialmente, na história e saberes dos povos latinoamericanos, tanto nos originários que guardam seu conhecimento em uma tradição anterior à chegada dos europeus, quanto aqueles que se constituíram a partir desse encontro, vivendo e revivendo em resistência a violência do passado colonial cujas raízes ainda estão sob nossos pés. Interessa-se por formas de vida comunais que vêm, insistente e corajosamente, resistindo ao longo dos anos e confrontando diretamente a crença da cultura ocidental no progresso e no projeto civilizatório que eliminou uma série de povos, e com eles, seus saberes, substituindo-os por um currículo com origens ocidentalizadas

Poiésis, Niterói, v. 20, n. 33, jan./jun. 2019. 
que, muitas vezes, pouca relação se estabelece com conhecimento outros. Busca na ideia de autonomia e liberdade fazer frente a esse processo que assombra o território latinoamericano desde os primórdios de sua constituição e busca imaginar novas formas de vida. Busca também na horizontalidade de saberes encontrar novas maneiras de compartilhar conhecimento, pensa nessa horizontalidade como uma mesa onde podem ser colocado saberes e conhecimentos diversos, sem hierarquização. A mesa é figura e ponto importante.

O povo original da floresta é o povo indígena. As nossas tribos são a gente que sempre viveu na floresta, mesmo os povos que vivem em região que não é de floresta grande como a da Amazônia, os que são do cerrado, os que são de região de capoeira, são povos da floresta, são povos do mato, e a cultura do nosso povo é uma cultura que tem economia, que tem toda a organização dela em cima do que a natureza oferece, em cima do que a natureza dá para os homens. [3]

Em meio às crises cultural, econômica, sistêmica, ambiental e aos desafios globais que essas crises impõem, surge uma questão: por que retornar - talvez tardiamente - às experiências de organização de vida comunitária provenientes de tradições culturais de alguns povos originários na América Latina? Como fazer isso partindo da experiência autocrítica, que assume a própria ignorância e também o desejo de aprendizagem dialógica, de autoquestionamento que reconhece os tipos de saber e de conhecimento construídos para além das lógicas acadêmica e científica, reconhecidas e promovidas conforme os paradigmas da cultura ocidental? Como fazer isso sem reproduzir - ainda que com as meIhores intenções de reconhecimento e horizontalidade - as lógicas extrativistas de conhecimento e de vitalidade do outro? [4] 
Criada pelo artista Fábio Tremonte em São Paulo, a Escola da Floresta não possui uma sede fixa, não tem paredes, cadeiras, mesas ou projetores, não tem refeitório nem banheiros, professores nem alunos, provas nem conteúdo programado. Em se tratando de forma, inclusive, ela é mutante. Ela borra as linhas distintivas entre autoridade e liberdade, entre escola e processo artístico, entre artista e educador, entre aluno e professor. A ausência de uma forma física, ou de um programa permanente implica, em alguma medida, em uma desobediência.

Para Fábio Tremonte, o encontro e a construção de esferas públicas são de grande importância para a constituição da Escola da Floresta, para além de seu conteúdo, que é calcado e baseado nos povos latino-americanos. Desse modo, Tremonte provoca uma relação entre a forma e aquilo que é ensinado, apresentado ou, simplesmente, posto à vista. Politicamente, seu conteúdo lida com questões que dificilmente são abordadas em escolas primárias, secundárias e universidades, além de serem pouco debatidas, também, no meio artístico. [2]

Ninguém pode antecipar a potência de um encontro. [5]

$* * *$

\section{Pedagogia canibal}

Quando dois corpos distintos posicionam-se frente a frente, cada um vem carregado do que se é. O outro é acessado a partir de nossas experiências, pensamentos, convicções etc. Entretanto, há uma brecha, um espaço, uma fresta que se estabelece, separa e une. Essa fresta é o espaço de encontro, no qual um fluxo de informações e trocas vai se formar, possibilitando o surgimento de diálogos, embates, conflitos.

Poiésis, Niterói, v. 20, n. 33, jan./jun. 2019. 
Em que consiste essa sociabilidade do Sul? Em primeiro lugar, é um impulso vital, nãoracional. Uma vontade de viver, um querer viver. Mas não viver de qualquer modo, e sim afirmando um tipo de vínculo, um tipo de existência, uma certa ideia de felicidade: um estar-juntos antropológico. É também um conjunto de saberes e estratégias para reproduzir esses vínculos, essas formas de vida. [6]

A figura da floresta é importante na configuração da escola, pois remete à origem e formação da América latina nesses cinco séculos, desde a chegada e intervenção européia, sugerindo uma multiplicidade cultural tão complexa quanto aquela encontrada nas florestas, um lugar de saberes e conhecimentos possíveis de gerar transformações efetivas, tanto sociais e políticas, quanto pessoais. O que possibilitaria isto é o confronto do modo de vida capitalista-ocidentalizado com os daqueles que lutam e resistem, recriando seus territórios e modos de viver.

$* * *$

Por isso a importância de reaprendermos a ativar a capacidade do encontro, de estar e permanecer juntos, de criar um ambiente com sua cultura, suas infraestruturas, seus códigos e sua economia, para que sejamos capazes de dar sustentação no tempo às práticas e aos valores que desejamos reverberar. [7]

Os encontros podem se configurar de diferentes maneiras, como viagens, passeios, caminhadas, culinária, projeção de filmes, contação de histórias, leituras de textos, produções gráficas, conversas e, também, através de colaboração de coletivos e/ou outras pessoas que sintam-se impulsionados em estabelecer relações com os projetos desenvolvidos e a propor outras possibilidades.

$* * *$ 
É perceptível o desejo da Escola da Floresta em se desdobrar, expandir-se em uma multiplicidade de sei-lá-o-quê, formular problemas e construir lugares de fala horizontalizados. [2]

$* * *$

Para aprender é necessário desacelerar. Sair do ritmo urbano e se colocar com todo o corpo à mercê de outras lógicas do tempo, dos intercâmbios pessoais e afetivos, do que ocorre como possibilidade quando um plano pré-desenhado falhar ou - afortunadamente - não se cumprir como o previsto. O tempo não produtivo. O tempo centenário. O tempo fora do calendário gregoriano. O tempo não ditado pelo trabalho humano. [4]

Radicalizando, a Escola da Floresta é um pensamento, uma consciência do gesto radical, imprescindível ao nosso tempo. Tempo de golpe, de esquecimento, de repressão, de ingerência, de contrarrevoluções. E se for assim, ela é claramente uma atitude política cal- cada na ideia de recomeçar. E recomeçar nunca é recomeçar alguma coisa. Nem retomar um assunto ali onde a gente o tinha deixado. O que a gente recomeça é sempre outra coisa. É sempre inaudito. Porque não é o passado que nos impele a isso, mas precisamente o que nele não adveio. E porque somos também nós mesmos, então, que recomeçamos. Recomeçar quer dizer: sair da suspensão. Restabelecer o contato entre nossos devires. Partir, de novo, dali onde estamos, agora. [2]

$* * *$

Outras coletividades, nas quais se incluem as não humanas, também dialogam. Outras coletividades nas quais os ritmos e os ciclos não são aqueles que predominam no imaginário do cotidiano urbano. [4]

Poiésis, Niterói, v. 20, n. 33, jan./jun. 2019. 
É, precisamente porque o que recomeçamos é sempre outra coisa, que falar sobre a Floresta faz dela uma experiência política do presente. Talvez uma das mais urgentes e necessárias. A floresta é, aqui, a metáfora da insurreição. É o ecossistema que insiste em se rebelar contra as transformações impostas pelo poder constituído do capital. [2]

A Escola da Floresta é um projeto em processo que busca gerar relações e, principalmente, aprender com as diferentes formas de luta e resistência latino-americanas e seus habitantes através do reconhecimento do outro e das diferenças culturais, geográficas, em todo esse território, da análise daquilo que nos une e que, também, nos afasta, nos diferencia e nos aproxima, tentando criar uma maior rede de troca de saberes como forma de aprender com a América Latina.

[...] pensar outras temporalidades e outras formas de vida esbarra em condições que costumam ser pouco flexíveis ou pouco dispostas a modificar seus tempos e objetivos de produtividade: institucional, programática, profissional, cultural. [4]

[...] artistas estão produzindo escolas como (se fossem) escolas de arte, mas escolas que não são de arte. Há nisso, ao mesmo tempo, uma dose interessante de desobediência civil - com relação à arte - e um alto grau de imaginação institucional - no que diz respeito à educação -, e vice-versa. [8]

$* * *$

Todas essas considerações também nos fazem refletir sobre o rumo que pode tomar essa escola, sobre quais tipos de ações e desdobramentos ela pode ter, os espaços que pode ocupar, os textos que pode compartilhar, as lutas em que pode se envolver. Por ser inseparável do eu (do artista) e do mundo, ela pode estabelecer zonas de indistinção, de 
intensidade e de fracasso. Lacunas de tempo também, entre uma aparição e outra. A Escola da Floresta é um pensamento porque ela pode ou não se materializar, ela pode ou não se infiltrar no quotidiano anestesiado das pessoas, ela pode ou não continuar existindo. E aí reside a sua força. [2]

[1] A partir de junho de 2019, a Escola da Floresta passa a ocupar um espaço físico fixo na cidade de São Paulo

[2] Kamilla Nunes | Embarcação | Dissertação de mestrado apresentado no departamento de artes visuais da Udesc [Universidade do Estado de de Santa Catarina]

[3] Ailton Krenak | A Aliança dos Povos da Floresta | Encontros | Azougue Editorial

[4] Sofia Olascoaga | Desaprender, perguntar-se, escutar: Uma pedagogia da incerteza? | Dias de Estudo | Incerteza Viva | 32a Bienal de São Paulo

[5] Comitê Invisível | Eles querem nos obrigar a governar, mas não vamos cair nessa provocação | Crise e Insurreição | N-1

[6] Amador Fernández-Savater | Pós-capitalismo: a dimensão sensível | http://outraspalavras.net/posts/pos-capitalismo-a-dimensao-sensivel/

[7] Henrique Parra | Tecnologias de pertencimento e produção do comum: ocupas, praças e jardins | https://urucum.milharal.org/2017/08/23/tecnologias-depertencimento-e-producao-do-comum-ocupas-pracas-e-jardins/

[8] Mônica Hoff | Notas para a construção de teorias refutáveis, pedagogias sem importância e escolas de garagem, ou: um bom nome para o amor | Fábrica de Conocimiento | Escuela de Garaje 